OPEN ACCESS

Edited by:

Tune Pers,

University of Copenhagen, Denmark

Reviewed by:

Jin Kwon Jeong,

George Washington University,

United States

Brandon L. Roberts,

University of Massachusetts Amherst,

United States

Paul Kievit,

Oregon Health and Science University,

United States

*Correspondence:

Thomas W. Gettys

Thomas.gettys@pbrc.edu

Specialty section:

This article was submitted to

Neuroendocrine Science,

a section of the journal

Frontiers in Endocrinology

Received: 10 September 2021 Accepted: 12 November 2021

Published: 30 November 2021

Citation:

Fang $\mathrm{H}$, Stone $K P$, Forney $L A$, Wanders $D$ and Gettys TW

(2021) Nutritional Regulation of

Hepatic FGF21 by Dietary

Restriction of Methionine.

Front. Endocrinol. 12:773975.

doi: 10.3389/fendo.2021.773975

\section{Nutritional Regulation of Hepatic FGF21 by Dietary Restriction of Methionine}

\author{
Han Fang ${ }^{1}$, Kirsten P. Stone ${ }^{1}$, Laura A. Forney ${ }^{2}$, Desiree Wanders ${ }^{3}$ \\ and Thomas W. Gettys ${ }^{1 *}$ \\ ${ }^{1}$ Laboratory of Nutrient Sensing and Adipocyte Signaling, Pennington Biomedical Research Center, Baton Rouge, LA, United States, \\ 2 Department of Kinesiology, Houston Baptist University, Houston, TX, United States, ${ }^{3}$ Department of Nutrition, Georgia State \\ University, Atlanta, GA, United States
}

FGF21 is a potent metabolic regulator of energy balance, body composition, lipid metabolism, and glucose homeostasis. Initial studies reported that it was increased by fasting and the associated increase in ketones, but more recent work points to the importance of dietary protein and sensing of essential amino acids in FGF21 regulation. For example, dietary restriction of methionine produces a rapid transcriptional activation of hepatic FGF21 that results in a persistent 5- to 10-fold increase in serum FGF21. Although FGF21 is a component of a complex transcriptional program activated by methionine restriction (MR), loss-of-function studies show that FGF21 is an essential mediator of the resulting effects of the MR diet on energy balance, remodeling of adipose tissue, and enhancement of insulin sensitivity. These studies also show that FGF21 signaling in the brain is required for the MR diet-induced increase in energy expenditure (EE) and reduction of adiposity. Collectively, the evidence supports the view that the liver functions as a sentinel to detect and respond to changes in dietary amino acid composition, and that the resulting mobilization of hepatic FGF21 is a key element of the homeostatic response. These findings raise the interesting possibility that therapeutic diets could be developed that produce sustained, biologically effective increases in FGF21 by nutritionally modulating its transcription and release.

\footnotetext{
Keywords: methionine restriction, protein restriction, energy expenditure, essential amino acids (EAA), nutrient sensing mechanisms
}

\section{OVERVIEW}

The mammalian Fibroblast growth factors ( $F g f)$ include an intracellular subfamily (Fgf11-14), a hormone-like subfamily ( $F g f 15 / 19 / 21 / 23)$, and a canonical subfamily (Fgf1-10, Fgf16-18, and Fgf20) (1). The Fgffamily arose from an ancestral $F g f$ gene (e.g., $F g f 13$ ) during vertebrate evolution through two distinct gene and genome duplication events $(2,3)$. The resulting expansion diversified the signaling capabilities of Fof family members, transforming them into ubiquitous regulators of developmental and metabolic processes. Canonical FGFs act locally as paracrine agents while hormonal FGFs are released into the circulation and function in an endocrine manner. The initial recognition of canonical FGFs as growth factors came after their isolation from the pituitary $(4,5)$ 
and from conditioned liver cell media (6). The remaining FGFs were identified using degenerative primers and homology-based PCR in conjunction with searches of DNA databases for homologous sequences (7). Canonical FGFs act through heparin-binding sites that stabilize their binding to FGF receptors. In contrast, hormone-like FGFs acquired endocrine functions by losing the heparin binding requirement and acquiring the ability to bind to their receptors using $\beta$ Klotho as a cofactor. FGF receptors are ubiquitously expressed across multiple tissues, but the expression of $\beta$ Klotho is far more restricted. This provides a mechanism to limit the target tissues of endocrine FGFs to specific sites. Of particular interest is the endocrine FGF, Fgf21, which came into sharp focus after it was discovered and shown to have beneficial effects on energy balance, insulin signaling, glucose uptake, and lipid metabolism (8-11). These properties inspired great enthusiasm for development of FGF21-based therapies for treatment of metabolic disease. The goal of this minireview is to briefly summarize recent efforts in that arena, the obstacles encountered, and outline an alternative approach to obtaining the beneficial metabolic effects of FGF21 through chronic nutritional modulation of endogenous FGF21 expression.

\section{BIOLOGICAL EFFECTS OF EXOGENOUS FGF21}

FGF21 was identified in cDNA from mouse embryos, found to be highly expressed in mouse liver (12), and shown to enhance glucose uptake in 3T3-L1 adipocytes through an insulinindependent increase in Glut1 expression (10). Administration of FGF21 to genetically obese rodents reduced their body weights, lowered blood glucose and plasma triglycerides, and reduced fasting insulin (10). These metabolic effects were recapitulated in transgenic Fgf21- overexpressing mice (10) and in C57BL/6J mice treated with FGF21 via osmotic minipumps (8). FGF21 increased food intake per unit body weight in these studies but was still able to reduce body weight because it simultaneously increased EE (8). FGF21 increased thermogenic gene expression in white adipose tissue while reducing lipogenic genes in the liver (8). These findings were extended to C57BL/6J mice fed a high fat diet where FGF21 also improved overall insulin sensitivity by decreasing hepatic glucose production and increasing insulindependent glucose uptake in adipose tissue (11). FGF21 produced these diverse effects through a combination of centrally-mediated effects on sympathetic outflow (13), peripherally-mediated effects on glucose uptake in adipose tissue (14-18), suppression of hepatic glucose production (11), and improvements in biomarkers of metabolic health that are secondary to FGF21-dependent reductions in adiposity. FGF21 also proved effective in non-human primates, as daily injections of the hormone in diabetic rhesus monkeys reproduced the beneficial metabolic effects of FGF21 observed in rodents (9). Collectively, these studies with pre-clinical models provided a compelling rationale for developing FGF21-based pharmacotherapies for metabolic disease.

\section{TRANSLATIONAL RESPONSES TO FGF21 ANALOGS AND MIMETICS}

The relatively short biological half-life of FGF21 (19) and its conformational instability in solution presented significant logistical impediments to using native FGF21 in the clinic (20). Efforts to re-engineer the FGF21 molecule to improve its formulation stability and biopharmaceutical properties have been successful and multiple labs have developed FGF21 analogs or receptor mimetics that are stable in solution, have long biological half-lives, and show minimal toxicology (21-25). In addition, pre-clinical studies with rodents and non-human primates have verified that several FGF21 analogs and mimetics successfully reproduce the full range of metabolic benefits produced by the native molecule $(19,20,26-30)$. Many of the FGF21 analogs and mimetics have progressed to clinical trials in patients with type 2 diabetes [see review by (31)]. However, the primary end points of improved glycemic control have not been met, although significant reductions in circulating lipids, hepatic fat, and body weight were documented in two studies $(27,32)$. In studies of patients with non-alcoholic steatohepatitis (NASH), pegylated versions of FGF21 produced significant decreases in hepatic fat, markers of hepatic fibrosis, and liver injury $(33,34)$. Although the FGF21 analogs were generally well tolerated, one of the analogs increased blood pressure and heart rate and produced modest increases in circulating markers of bone resorption (27). The latter safety concern is consistent with pre-clinical findings showing that transgenic Fgf21 mice had higher rates of bone resorption and lower rates of bone formation $(35,36)$. Another adverse effect was the generation of FGF21 antibodies caused by the immunogenicity of the FGF21 analog $(33,34)$. This could be a more pervasive problem if the engineered structures of other FGF21 analogs and mimetics are recognized as foreign by the immune system, particularly since their use is expected to involve chronic treatments. It is clear that the safety issues associated with the long-term use of these drugs will need to be thoroughly examined going forward. Equally concerning is whether there are fundamental differences in the way non-human primates and humans respond to FGF21 in terms of glucose lowering (31). Viewed collectively, it appears that these unresolved issues will delay implementation of FGF21based mimetics for broad-based treatment of metabolic disease for now.

A potential solution to the obstacles encountered with injectable pharmacotherapies based on FGF21 mimetics is provided by an approach that involves chronically increasing endogenous FGF21 transcription and release from the liver. Discovery research over the last decade has shown that the liver functions as a sentinel to monitor and respond to changes in dietary composition, particularly the protein and amino acid content of the diet (37-39). Reductions in the overall protein content of the diet or the amounts of specific essential amino acids (EAA) produce a rapid transcriptional activation of the hepatic Fgf21 gene, and the increased expression of FGF21 is maintained for as long as the experimental diet is consumed (40, 41). The reductions in dietary EAA content needed to 
transactivate Fgf21 without also compromising growth and development occur within a narrow concentration range, but within these defined ranges the resulting increase in circulating FGF21 reproduces the full range of metabolic responses produced by treatment with exogenous FGF21 (42). Therefore, the development of therapeutic diets that produce the required degree of EAA restriction provides a potentially attractive approach to obtain the benefits of FGF21 biology through dietinduced modulation of its expression. The specific dietary modifications that produce these effects have been rigorously established in recent years and potential approaches to their implementation will be the subject of the current minireview.

\section{PHYSIOLOGICAL REGULATION OF FGF21 EXPRESSION}

The physiological context in which FGF21 regulation was originally identified was fasting or starvation when the associated increases in fatty acids and ketones activated PPAR $\alpha$ and increased transcription of the hepatic Fgf 21 gene $(43,44)$. Ketogenic diets were proposed as important regulators and FGF21 was originally dubbed as a starvation hormone (4345). However, except under extreme conditions, the significance of fasting and ketones now seems relatively unimportant in regulation of human FGF21 (46-48). Given the impact of FGF21 on dysfunctional glucose and lipid metabolism, a concerted effort has been made to identify the key metabolic states, physiological signals, hormones, signaling pathways, and transcription factors responsible for regulation of Fgf21 (49-60). In vivo studies have been complemented by extensive in vitro work to identify and dissect the sensing and signaling systems responsible for transcriptional activation of the Fgf21 gene (53, $55,61-65)$. While it is beyond the scope of this minireview to provide a detailed accounting of the many signaling systems providing regulatory input to the $F g f 21$ gene, several excellent reviews are available $(45,62,66-71)$. A particularly useful illustration of the regulatory complexity of Fgf21 transcription was presented by Erickson and Moreau (66), who used bioinformatic tools to map the response elements contained within the 5'-flanking region of $4600 \mathrm{bp}$ of the transcription start site for the human, mouse, and rat Fgf21 gene. They identified multiple copies of binding sites for no fewer than 10 nuclear receptors and/or transcription factors in the promoters. In addition, multiple sensing and signaling systems provide input to each nuclear receptor and transcription factor so this map of response elements does not capture the true complexity of Fgf21 regulation (66). For example, ER stress signals through PERK and eIF2 $\alpha$ to increase transcriptional activation of Fgf 21 through ATF4 $(56,72)$, but sensing of essential amino acids through GCN2 and eIF2 $\alpha$ can also signal through ATF4 to increase Fgf21 expression (73). Viewed collectively, the physiological state of the liver at any point in time is providing a vast amount of regulatory input to the $F g f 21$ gene. However, from a therapeutic viewpoint, the most important question is whether the prevailing rate of $F g f 21$ transcription can be reset to a higher overall rate that chronically increases circulating FGF21 and produces the associated metabolic benefits.

\section{DIETARY REGULATION OF FGF21 EXPRESSION}

Dietary protein restriction and methionine restriction (MR) produce a comparable series of behavioral, physiological, biochemical, and transcriptional responses that result in a significant improvement in metabolic health [reviewed in $(37,38$, 74-76)]. The responses include increased energy intake and expenditure, decreased adiposity, enhanced insulin sensitivity, and reduction in circulating and tissue lipids. A common model used to study protein restriction involves reducing the dietary concentration of casein from $20 \%$ to $5 \%$ (77). Dietary MR involves formulation of diets from elemental amino acids, reducing the methionine content from $0.86 \%$ to $0.17 \%$, and eliminating cysteine. Both dietary regimens result in a similar reduction in methionine and cysteine intake $(77,78)$, and both diets increase expression and release of hepatic FGF21 $(77,79,80)$. Rodent studies show that protein restriction increases circulating FGF21 within $24 \mathrm{~h}$ (77) while chronic protein restriction permanently increased FGF21, enhanced metabolic health, and extended lifespan (81). The mouse longevity study (81) used an integrative modeling approach called the Geometric Framework with groups of mice fed one of 25 diets that systematically varied the protein, carbohydrate, and fat content. They found that FGF21 was maximally elevated under low protein intakes and the increased FGF21 was strongly correlated with improvements in biomarkers of metabolic health (41). Dietary MR produces a comparable 5- to 10fold increase in circulating FGF21 within $6 \mathrm{~h}$ of initiating the MR diet (72) and the increase in FGF21 is maintained for as long as the MR diet is consumed $(80,82,83)$. Based on what is known about FGF21 biology and the responses of rodents to exogenous or overexpressed FGF21, it is attractive to speculate that transcriptional activation of hepatic $F g f 21$ by protein restriction or MR provides the causative link to the metabolic phenotypes produced by each diet. This hypothesis has been systematically addressed using multiple loss of function approaches with each diet. The Morrison lab (77) established that FGF21 was the endocrine signal linking protein restriction to increased $\mathrm{EE}$, and showed in later work that FGF21 was also necessary for the low protein diet to increase thermogenic gene expression in brown and white adipose tissue (84). Low protein diets also enhanced glucose homeostasis in mice and FGF21 was necessary for this effect (85). FGF21 signaling in the brain increases EE by increasing sympathetic nervous system outflow (13) and mice that lack either Fgf21 or FGF21 signaling in the brain are unable to increase $\mathrm{EE}$ in response to protein restriction. Parallel studies of dietary MR have been conducted with $\mathrm{Fg} 2 \mathrm{I}^{-1}$ mice and mice with ablation of central FGF21 signaling. In Fgf $21^{-1-}$ mice, the ability of dietary MR to increase EE and enhance thermogenic gene expression in brown adipose tissue (BAT) and white adipose tissue (WAT) was totally dependent on FGF21, while effects of dietary MR to reduce lipogenic gene expression in the liver did not require FGF21 (40). Deletion of $\beta$ Klotho in the CNS also 
completely blocked the ability of dietary MR to increase EE and remodel adipose tissue (86), supporting the view that the increase in FGF21 produced by dietary MR acts primarily in the brain to affect energy balance. Viewed together, these findings make a compelling case that it is possible to obtain a rapidly deployed but long-lasting set of metabolic responses to FGF21 by diet-induced transcriptional activation of the hepatic gene. An important remaining question is whether therapeutic diets can be developed that produce chronic, biologically effective increases in FGF21 in a clinical setting that produce some or all beneficial metabolic effects attributed to the hormone.

\section{PATHS TO IMPLEMENTATION OF DIETARY MR TO CHRONICALLY INCREASE FGF21}

Casein restriction to $5 \%$ faithfully reproduces the full metabolic profile of dietary methionine restriction and restricts sulfur amino acids to a similar extent. Therefore, it seems likely that dietary casein restriction is producing most of its biological effects by limiting dietary methionine intake. An important implication of this conclusion is that it supports the feasibility of deriving the therapeutic benefits of dietary MR by restricting protein intake in conjunction with a careful accounting of methionine content of the various proteins that make up the diet. The most straightforward way to restrict methionine is to formulate amino acid-based diets that reduce the methionine content to $\sim 0.17 \%$ and eliminate cystine. This is the approach used in pre-clinical studies of MR because rodents readily adapt to consumption of these diets. However, this approach works poorly in humans because of poor tolerance of the bitter, metallic taste of elemental amino acids. The medical food, Homine ${ }^{\circledR}-2$ is a methionine free mixture of essential amino acids that was developed to provide nutritional support to patients with pyridoxine-insensitive hypercystinuria or hypermethionemia (87). Although Hominex-2 was moderately effective in increasing fat oxidation and reducing hepatic lipid content in patients with metabolic syndrome, the high withdrawal rates from the study and subsequent feedback made it clear that poor palatability was a significant drawback (88). A second major drawback to the use of Hominex-2 is that it contains significant amounts of cystine, which effectively spares methionine and lessens the severity of the methionine restriction (89). As shown by several authors, the addition of even small amounts of cystine to MR diets effectively reverses the metabolic effects of $\operatorname{MR}(72,90,91)$. For example, in work using diets containing $0.17 \%$ methionine, the addition of $0.2 \%$ cystine completely reversed the ability of the $0.17 \%$ methionine diet to increase EE and reduce fat mass (72). Therefore, a critical question to be answered is how much dietary cystine can be present for a given amount of MR and still preserve the effects of the methionine restriction alone. In earlier work, the upper threshold of methionine restriction was $\sim 0.25 \%$ methionine when no cystine was present in the diet (42). Recent work suggests that protein restriction producing reductions of methionine and cystine in the range of $0.24 \%$ to $0.26 \%$ retain full efficacy (78). Together these findings suggest that careful attention to the total amount of methionine and cystine will be needed to implement a proteinrestricted diet that produces therapeutically effective reductions in sulfur amino acids.

Lastly, an alternative approach to dietary methionine restriction was recently described which reduced the methionine and cystine content of casein by targeted, oxidative deletion of the sulfur amino acids in the intact protein (92). The advantage of this approach is that the sulfur amino acid-depleted casein maintains its palatability and can produce the metabolic benefits of protein restriction without reducing overall protein content of the diet. Proof-of-concept studies comparing methionine-depleted casein-based diets to elemental amino acidbased methionine restricted diets established the feasibility of this approach and showed that the beneficial metabolic effects of methionine restriction were reproduced by the oxidized caseinbased MR diets (92). It will be interesting in future studies to determine whether combinations of mild protein restriction coupled with targeted methionine depletion of the proteins to be restricted can be implemented to produce therapeutically effective diets for the treatment of obesity and metabolic disease.

\section{CONCLUSIONS AND FUTURE DIRECTIONS}

Figure 1 provides a conceptual model of the anatomical organization of the sensing and signaling systems that link increased transcription and release of FGF21 from the liver to the metabolic responses produced by dietary methionine restriction. We propose that FGF21 is the critical mediator of all the physiological responses to MR except its effects on hepatic lipid metabolism. An important remaining objective is to identify the sites where FGF21 is acting to produce the components of the overall biological response to dietary MR. For example, are the documented effects of dietary MR on insulin sensitivity in adipose tissue the result of direct actions of FGF21 signaling in this tissue, or are they secondary to the FGF21-mediated remodeling of adipose tissue that results from FGF21-dependent increases in SNS outflow to adipose tissue? These questions could be addressed in future studies using a tissue-specific loss of function approach that alternatively and selectively deletes FGF21 signaling in adipose tissue or the hypothalamus.

Although significant progress has been made in identifying specific cell types within the hypothalamus that respond to FGF21 (93-95), much additional work is needed to precisely identify the population(s) of neurons that link MR-dependent increases in FGF21 to the resulting biological responses.

Success in these experiments will guide the development of targeting vectors and the corresponding loss of function models that will be needed to provide definitive in vivo identification of the neurons linking MR-dependent increases in FGF21 to SNS activation. An additional challenging aspect of these experiments will be the interdependence of the multiple components of the phenotype (e.g., adiposity, insulin sensitivity) and correctly mapping the loss of MR-dependent responses to the anatomical site where FGF21 is acting to produce them. 


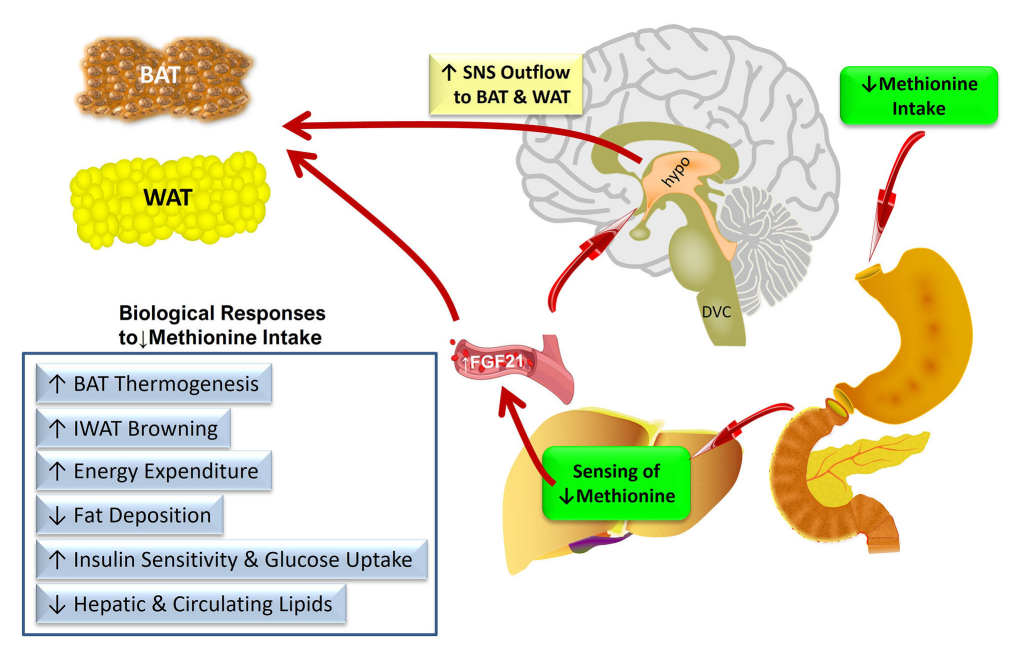

FIGURE 1 | Conceptual model of the anatomical organization of the sensing and signaling systems that link increased transcription and release of FGF21 from the liver to the metabolic responses produced by dietary methionine restriction. Abbreviations used - BAT, brown adipose tissue; IWAT, inguinal white adipose tissue; SNS, sympathetic nervous system; DVC, dorso-vagal complex; hypo, hypothalamus.

The path to translational implementation of dietary MR using either protein restriction or targeted oxidation of methionine and cysteine in intact proteins will involve producing and testing the acceptability and efficacy of the resulting diets. A more practical path forward might be to use a combination of both approaches to develop a limited but highly palatable group of modified proteins that could be the basis for a therapeutic diet that is consumed under medical supervision for a specified interval. The successful implementation of dietary MR in a translational context will require the collaboration of food scientists to produce palatable modified protein, nutritionists to make sure methionine and cysteine are kept within the required range, and translational scientists to evaluate the safety and efficacy of the resulting diets.

\section{AUTHOR CONTRIBUTIONS}

HF, KS, LF, DW, and TG contributed to the writing and editing of the manuscript and agree to be held accountable for the content of the work. All authors contributed to the article and approved the submitted version.

\section{REFERENCES}

1. Itoh N, Ornitz DM. Evolution of the Fgf and Fgfr Gene Families. Trends Genet (2004) 20:563-9. doi: 10.1016/j.tig.2004.08.007

2. Itoh N, Ornitz DM. Functional Evolutionary History of the Mouse Fgf Gene Family. Dev Dyn (2008) 237:18-27. doi: 10.1002/dvdy. 21388

3. Itoh N. Hormone-Like (Endocrine) Fgfs: Their Evolutionary History and Roles in Development, Metabolism, and Disease. Cell Tissue Res (2010) 342:1-11. doi: 10.1007/s00441-010-1024-2

4. Gospodarowicz D, Jones KL, Sato G. Purification of a Growth Factor for Ovarian Cells From Bovine Pituitary Glands. Proc Natl Acad Sci USA (1974) 71:2295-9. doi: 10.1073/pnas.71.6.2295

\section{FUNDING}

This work was supported by NIH DK-096311 (TWG). This work also made use of the Genomics Core Facility supported by NIH P20-GM103528 (TWG) and NIH 2P30 DK072476. This research project used the Transgenic and Animal Phenotyping core facilities that are supported in part by the NORC (NIH 2P30 DK072476) and by an equipment grant (S10OD023703) from the NIH. This work was also supported by NIH DK-098918; Center for Neuroinflammation and Cardiometabolic Diseases Seed Grant (DW).

\section{ACKNOWLEDGMENTS}

Many undergraduate students supported the authors' work summarized in this minireview and the important contributions of the following to that work over the last 10 years is gratefully acknowledged (Leighann Vincik, Alicia M. Vick, Amanda N. Gibson, Manda Orgeron, Nancy T. Van, Alicia Pierse, Kelly N. Dille, Cory C. Cortez, Lucie F. Calderon, Mollye Baker, and Corey Black).

5. Gospodarowicz D, Moran J. Effect of a Fibroblast Growth Factor, Insulin, Dexamethasone, and Serum on the Morphology of BALB/C 3T3 Cells. Proc Natl Acad Sci USA (1974) 71:4648-52. doi: 10.1073/pnas.71.12.4648

6. Dulak NC, Temin HM. A Partially Purified Polypeptide Fraction From Rat Liver Cell Conditioned Medium With Multiplication-Stimulating Activity for Embryo Fibroblasts. J Cell Physiol (1973) 81:153-60. doi: 10.1002/jcp.1040810204

7. Smallwood PM, Munoz-Sanjuan I, Tong P, Macke JP, Hendry SH, Gilbert DJ, et al. Fibroblast Growth Factor (FGF) Homologous Factors: New Members of the FGF Family Implicated in Nervous System Development. Proc Natl Acad Sci USA (1996) 93:9850-7. doi: 10.1073/pnas.93.18.9850

8. Coskun T, Bina HA, Schneider MA, Dunbar JD, Hu CC, Chen Y, et al. Fibroblast Growth Factor 21 Corrects Obesity in Mice. Endocrinology (2008) 149:6018-27. doi: 10.1210/en.2008-0816 
9. Kharitonenkov A, Wroblewski VJ, Koester A, Chen YF, Clutinger CK, Tigno $\mathrm{XT}$, et al. The Metabolic State of Diabetic Monkeys Is Regulated by Fibroblast Growth Factor-21. Endocrinology (2007) 148:774-81. doi: 10.1210/en.20061168

10. Kharitonenkov A, Shiyanova TL, Koester A, Ford AM, Micanovic R, Galbreath EJ, et al. FGF-21 as a Novel Metabolic Regulator. J Clin Invest (2005) 115:1627-35. doi: 10.1172/JCI23606

11. Xu J, Lloyd DJ, Hale C, Stanislaus S, Chen M, Sivits G, et al. Fibroblast Growth Factor 21 Reverses Hepatic Steatosis, Increases Energy Expenditure, and Improves Insulin Sensitivity in Diet-Induced Obese Mice. Diabetes (2009) 58:250-9. doi: $10.2337 / \mathrm{db} 08-0392$

12. Nishimura T, Nakatake Y, Konishi M, Itoh N. Identification of a Novel FGF, FGF-21, Preferentially Expressed in the Liver. Biochim Biophys Acta (2000) 1492:203-6. doi: 10.1016/s0167-4781(00)00067-1

13. Owen BM, Ding X, Morgan DA, Coate KC, Bookout AL, Rahmouni K, et al. FGF21 Acts Centrally to Induce Sympathetic Nerve Activity, Energy Expenditure, and Weight Loss. Cell Metab (2014) 20:670-7. doi: 10.1016/ j.cmet.2014.07.012

14. Adams AC, Cheng CC, Coskun T, Kharitonenkov A. FGF21 Requires Betaklotho to Act In Vivo. PloS One (2012) 7:e49977. doi: 10.1371/journal. pone.0049977

15. Ding X, Boney-Montoya J, Owen BM, Bookout AL, Coate KC, Mangelsdorf DJ, et al. Betaklotho Is Required for Fibroblast Growth Factor 21 Effects on Growth and Metabolism. Cell Metab (2012) 16:387-93. doi: 10.1016/ j.cmet.2012.08.002

16. Schlein C, Talukdar S, Heine M, Fischer AW, Krott LM, Nilsson SK, et al. FGF21 Lowers Plasma Triglycerides by Accelerating Lipoprotein Catabolism in White and Brown Adipose Tissues. Cell Metab (2016) 23:441-53. doi: 10.1016/j.cmet.2016.01.006

17. Owen BM, Mangelsdorf DJ, Kliewer SA. Tissue-Specific Actions of the Metabolic Hormones FGF15/19 and FGF21. Trends Endocrinol Metab (2015) 26:22-9. doi: 10.1016/j.tem.2014.10.002

18. BonDurant LD, Ameka M, Naber MC, Markan KR, Idiga SO, Acevedo MR, et al. FGF21 Regulates Metabolism Through Adipose-Dependent and -Independent Mechanisms. Cell Metab (2017) 25:935-44.e934. doi: 10.1016/ j.cmet.2017.03.005

19. Song LT, Zhu YL, Wang HY, Belov AA, Niu JL, Shi L, et al. Solid-Phase Pegylation Strategy for Protein Therapeutics Using a Potent FGF21 Analog. Biomaterials (2014) 35:5206-15. doi: 10.1016/j.biomaterials.2014.03.023

20. Kharitonenkov A, Beals JM, Micanovic R, Strifler BA, Rathnachalam R, Wroblewski VJ, et al. Rational Design of a Fibroblast Growth Factor 21Based Clinical Candidate, LY2405319. PloS One (2013) 8:e58575. doi: 10.1371/journal.pone.0058575

21. Hecht R, Li YS, Sun J, Belouski E, Hall M, Hager T, et al. Rationale-Based Engineering of a Potent Long-Acting FGF21 Analog for the Treatment of Type 2 Diabetes. PloS One (2012) 7:e49345. doi: 10.1371/journal. pone. 0049345

22. Mu J, Pinkstaff J, Li Z, Skidmore L, Li N, Myler H, et al. FGF21 Analogs of Sustained Action Enabled by Orthogonal Biosynthesis Demonstrate Enhanced Antidiabetic Pharmacology in Rodents. Diabetes (2012) 61:50512. doi: $10.2337 / \mathrm{db} 11-0838$

23. Huang J, Ishino T, Chen G, Rolzin P, Osothprarop TF, Retting K, et al. Development of a Novel Long-Acting Antidiabetic FGF21 Mimetic by Targeted Conjugation to a Scaffold Antibody. J Pharmacol Exp Ther (2013) 346:270-80. doi: 10.1124/jpet.113.204420

24. Weng Y, Ishino T, Sievers A, Talukdar S, Chabot JR, Tam A, et al. GlycoEngineered Long Acting FGF21 Variant With Optimal Pharmaceutical and Pharmacokinetic Properties to Enable Weekly to Twice Monthly Subcutaneous Dosing. Sci Rep (2018) 8:4241. doi: 10.1038/s41598-018-22456-w

25. Stanislaus S, Hecht R, Yie J, Hager T, Hall M, Spahr C, et al. A Novel FcFGF21 With Improved Resistance to Proteolysis, Increased Affinity Toward Beta-Klotho, and Enhanced Efficacy in Mice and Cynomolgus Monkeys. Endocrinology (2017) 158:1314-27. doi: 10.1210/en.2016-1917

26. Adams AC, Halstead CA, Hansen BC, Irizarry AR, Martin JA, Myers SR, et al. LY2405319, an Engineered FGF21 Variant, Improves the Metabolic Status of Diabetic Monkeys. PloS One (2013) 8:e65763. doi: 10.1371/journal. pone. 0065763
27. Talukdar S, Zhou Y, Li D, Rossulek M, Dong J, Somayaji V, et al. A LongActing FGF21 Molecule, PF-05231023, Decreases Body Weight and Improves Lipid Profile in Non-Human Primates and Type 2 Diabetic Subjects. Cell Metab (2016) 23:427-40. doi: 10.1016/j.cmet.2016.02.001

28. Zhao L, Niu J, Lin H, Zhao J, Liu Y, Song Z, et al. Paracrine-Endocrine FGF Chimeras as Potent Therapeutics for Metabolic Diseases. EBioMedicine (2019) 48:462-77. doi: 10.1016/j.ebiom.2019.09.052

29. Foltz IN, Hu S, King C, Wu X, Yang C, Wang W, et al. Treating Diabetes and Obesity With an FGF21-Mimetic Antibody Activating the Betaklotho/ FGFR1c Receptor Complex. Sci Transl Med (2012) 4:162ra153. doi: 10.1126/scitranslmed.3004690

30. Kolumam G, Chen MZ, Tong R, Zavala-Solorio J, Kates L, van Bruggen N, et al. Sustained Brown Fat Stimulation and Insulin Sensitization by a Humanized Bispecific Antibody Agonist for Fibroblast Growth Factor Receptor 1/Betaklotho Complex. EBioMedicine (2015) 2:730-43. doi: 10.1016/j.ebiom.2015.05.028

31. Geng L, Lam KSL, Xu A. The Therapeutic Potential of FGF21 in Metabolic Diseases: From Bench to Clinic. Nat Rev Endocrinol (2020) 16:654-67. doi: 10.1038/s41574-020-0386-0

32. Gaich G, Chien JY, Fu H, Glass LC, Deeg MA, Holland WL, et al. The Effects of LY2405319, an FGF21 Analog, in Obese Human Subjects With Type 2 Diabetes. Cell Metab (2013) 18:333-40. doi: 10.1016/j.cmet.2013.08.005

33. Charles ED, Neuschwander-Tetri BA, Pablo Frias J, Kundu S, Luo Y, Tirucherai GS, et al. Pegbelfermin (BMS-986036), Pegylated FGF21, in Patients With Obesity and Type 2 Diabetes: Results From a Randomized Phase 2 Study. Obes (Silver Spring) (2019) 27:41-9. doi: 10.1002/oby.22344

34. Sanyal A, Charles ED, Neuschwander-Tetri BA, Loomba R, Harrison SA, Abdelmalek MF, et al. Pegbelfermin (BMS-986036), A Pegylated Fibroblast Growth Factor 21 Analogue, in Patients With Non-Alcoholic Steatohepatitis: A Randomised, Double-Blind, Placebo-Controlled, Phase 2a Trial. Lancet (2019) 392:2705-17. doi: 10.1016/S0140-6736(18)31785-9

35. Wei W, Dutchak PA, Wang X, Ding X, Wang X, Bookout AL, et al. Fibroblast Growth Factor 21 Promotes Bone Loss by Potentiating the Effects of Peroxisome Proliferator-Activated Receptor Gamma. Proc Natl Acad Sci USA (2012) 109:3143-8. doi: 10.1073/pnas.1200797109

36. Wang X, Wei W, Krzeszinski JY, Wang Y, Wan YA. Liver-Bone Endocrine Relay by IGFBP1 Promotes Osteoclastogenesis and Mediates FGF21-Induced Bone Resorption. Cell Metab (2015) 22:811-24. doi: 10.1016/j. cmet.2015.09.010

37. Hill CM, Berthoud HR, Munzberg H, Morrison CD. Homeostatic Sensing of Dietary Protein Restriction: A Case for FGF21. Front Neuroendocrinol (2018) 51:125-31. doi: 10.1016/j.yfrne.2018.06.002

38. Anthony TG, Morrison CD, Gettys TW. Remodeling of Lipid Metabolism by Dietary Restriction of Essential Amino Acids. Diabetes (2013) 62:2635-44. doi: $10.2337 / \mathrm{db} 12-1613$

39. Efeyan A, Comb WC, Sabatini DM. Nutrient-Sensing Mechanisms and Pathways. Nature (2015) 517:302-10. doi: 10.1038/nature14190

40. Wanders D, Forney LA, Stone KP, Burk DH, Pierse A, Gettys TW. FGF21 Mediates the Thermogenic and Insulin-Sensitizing Effects of Dietary Methionine Restriction But Not Its Effects on Hepatic Lipid Metabolism. Diabetes (2017) 66:858-67. doi: 10.2337/db16-1212

41. Solon-Biet SM, Cogger VC, Pulpitel T, Heblinski M, Wahl D, McMahon AC, et al. Defining the Nutritional and Metabolic Context of FGF21 Using the Geometric Framework. Cell Metab (2016) 24:555-65. doi: 10.1016/ j.cmet.2016.09.001

42. Forney LA, Wanders D, Stone KP, Pierse A, Gettys TW. ConcentrationDependent Linkage of Dietary Methionine Restriction to the Components of Its Metabolic Phenotype. Obes (Silver Spring) (2017) 25:730-8. doi: 10.1002/ oby. 21806

43. Badman MK, Pissios P, Kennedy AR, Koukos G, Flier JS, Maratos-Flier E. Hepatic Fibroblast Growth Factor 21 Is Regulated by Pparalpha and Is a Key Mediator of Hepatic Lipid Metabolism in Ketotic States. Cell Metab (2007) 5:426-37. doi: 10.1016/j.cmet.2007.05.002

44. Inagaki T, Dutchak P, Zhao G, Ding X, Gautron L, Parameswara V, et al. Endocrine Regulation of the Fasting Response by Pparalpha-Mediated Induction of Fibroblast Growth Factor 21. Cell Metab (2007) 5:415-25. doi: 10.1016/j.cmet.2007.05.003 
45. Kliewer SA, Mangelsdorf DJ. Fibroblast Growth Factor 21: From Pharmacology to Physiology. Am J Clin Nutr (2010) 91:254S-7S. doi: 10.3945/ajen.2009.28449B

46. Galman C, Lundasen T, Kharitonenkov A, Bina HA, Eriksson M, Hafstrom I, et al. The Circulating Metabolic Regulator FGF21 Is Induced by Prolonged Fasting and Pparalpha Activation in Man. Cell Metab (2008) 8:169-74. doi: 10.1016/j.cmet.2008.06.014

47. Lauritzen ES, Svart MV, Voss T, Moller N, Bjerre M. Impact of Acutely Increased Endogenous- and Exogenous Ketone Bodies on FGF21 Levels in Humans. Endocr Res (2021) 46:20-7. doi: 10.1080/07435800.2020.1831015

48. Nygaard EB, Orskov C, Almdal T, Vestergaard H, Andersen B. Fasting Decreases Plasma FGF21 in Obese Subjects and the Expression of FGF21 Receptors in Adipose Tissue in Both Lean and Obese Subjects. J Endocrinol (2018) 239:73-80. doi: 10.1530/JOE-18-0002

49. Li Y, Wong K, Walsh K, Gao B, Zang M. Retinoic Acid Receptor Beta Stimulates Hepatic Induction of Fibroblast Growth Factor 21 to Promote Fatty Acid Oxidation and Control Whole-Body Energy Homeostasis in Mice. J Biol Chem (2013) 288:10490-504. doi: 10.1074/jbc.M112.429852

50. Dushay JR, Toschi E, Mitten EK, Fisher FM, Herman MA, Maratos-Flier E. Fructose Ingestion Acutely Stimulates Circulating FGF21 Levels in Humans. Mol Metab (2015) 4:51-7. doi: 10.1016/j.molmet.2014.09.008

51. Lundsgaard AM, Fritzen AM, Sjoberg KA, Myrmel LS, Madsen L, Wojtaszewski JFP, et al. Circulating FGF21 in Humans Is Potently Induced by Short Term Overfeeding of Carbohydrates. Mol Metab (2017) 6:22-9. doi: 10.1016/j.molmet.2016.11.001

52. Cyphert HA, Alonge KM, Ippagunta SM, Hillgartner FB. Glucagon Stimulates Hepatic FGF21 Secretion Through a PKA- and EPAC-Dependent Posttranscriptional Mechanism. PloS One (2014) 9:e94996. doi: 10.1371/ journal.pone.0094996

53. Adams AC, Astapova I, Fisher FM, Badman MK, Kurgansky KE, Flier JS, et al. Thyroid Hormone Regulates Hepatic Expression of Fibroblast Growth Factor 21 in a Pparalpha-Dependent Manner. J Biol Chem (2010) 285:14078-82. doi: $10.1074 /$ jbc.C110.107375

54. Girer NG, Murray IA, Omiecinski CJ, Perdew GH. Hepatic Aryl Hydrocarbon Receptor Attenuates Fibroblast Growth Factor 21 Expression. J Biol Chem (2016) 291:15378-87. doi: 10.1074/jbc.M116.715151

55. Jiang S, Yan C, Fang QC, Shao ML, Zhang YL, Liu Y, et al. Fibroblast Growth Factor 21 Is Regulated by the IRE1alpha-XBP1 Branch of the Unfolded Protein Response and Counteracts Endoplasmic Reticulum Stress-Induced Hepatic Steatosis. J Biol Chem (2014) 289:29751-65. doi: 10.1074/ jbc.M114.565960

56. Schaap FG, Kremer AE, Lamers WH, Jansen PL, Gaemers IC. Fibroblast Growth Factor 21 Is Induced by Endoplasmic Reticulum Stress. Biochimie (2013) 95:692-9. doi: 10.1016/j.biochi.2012.10.019

57. Salminen A, Kaarniranta K, Kauppinen A. Integrated Stress Response Stimulates FGF21 Expression: Systemic Enhancer of Longevity. Cell Signal (2017) 40:10-21. doi: 10.1016/j.cellsig.2017.08.009

58. Fisher FM, Kim M, Doridot L, Cunniff JC, Parker TS, Levine DM, et al. A Critical Role for Chrebp-Mediated FGF21 Secretion in Hepatic Fructose Metabolism. Mol Metab (2017) 6:14-21. doi: 10.1016/j.molmet.2016.11.008

59. Chen W, Hoo RL, Konishi M, Itoh N, Lee PC, Ye HY, et al. Growth Hormone Induces Hepatic Production of Fibroblast Growth Factor 21 Through a Mechanism Dependent on Lipolysis in Adipocytes. J Biol Chem (2011) 286:34559-66. doi: 10.1074/jbc.M111.285965

60. Kim H, Mendez R, Zheng Z, Chang L, Cai J, Zhang R, et al. Liver-Enriched Transcription Factor CREBH Interacts With Peroxisome ProliferatorActivated Receptor Alpha to Regulate Metabolic Hormone FGF21. Endocrinology (2014) 155:769-82. doi: 10.1210/en.2013-1490

61. Alonge KM, Meares GP, Hillgartner FB. Glucagon and Insulin Cooperatively Stimulate Fibroblast Growth Factor 21 Gene Transcription by Increasing the Expression of Activating Transcription Factor 4. J Biol Chem (2017) 292:5239-52. doi: 10.1074/jbc.M116.762922

62. De Sousa-Coelho AL, Marrero PF, Haro D. Activating Transcription Factor 4Dependent Induction of FGF21 During Amino Acid Deprivation. Biochem J (2012) 443:165-71. doi: 10.1042/BJ20111748

63. Stone KP, Ghosh S, Kovalik JP, Orgeron M, Wanders D, Sims LC, et al. The Acute Transcriptional Responses to Dietary Methionine Restriction Are Triggered by Inhibition of Ternary Complex Formation and Linked to
Erk1/2, Mtor, and ATF4. Sci Rep (2021) 11:3765. doi: 10.1038/s41598-02183380-0

64. Tong X, Zhang D, Buelow K, Guha A, Arthurs B, Brady HJ, et al. Recruitment of Histone Methyltransferase G9a Mediates Transcriptional Repression of Fgf21 Gene by E4BP4 Protein. J Biol Chem (2013) 288:5417-25. doi: 10.1074/ jbc.M112.433482

65. Wang Y, Solt LA, Burris TP. Regulation of FGF21 Expression and Secretion by Retinoic Acid Receptor-Related Orphan Receptor Alpha. J Biol Chem (2010) 285:15668-73. doi: 10.1074/jbc.M110.102160

66. Erickson A, Moreau R. The Regulation of FGF21 Gene Expression by Metabolic Factors and Nutrients. Horm Mol Biol Clin Investig (2016) 30:114. doi: $10.1515 / \mathrm{hmbci}-2016-0016$

67. Perez-Marti A, Sandoval V, Marrero PF, Haro D, Relat J. Nutritional Regulation of Fibroblast Growth Factor 21: From Macronutrients to Bioactive Dietary Compounds. Horm Mol Biol Clin Investig (2016) 30:1-16. doi: 10.1515/hmbci-2016-0034

68. Kim KH, Lee MS. FGF21 as a Mediator of Adaptive Responses to Stress and Metabolic Benefits of Anti-Diabetic Drugs. J Endocrinol (2015) 226:R1-16. doi: 10.1530/JOE-15-0160

69. Fisher FM, Maratos-Flier E. Understanding the Physiology of FGF21. Annu Rev Physiol (2016) 78:223-41. doi: 10.1146/annurev-physiol-021115-105339

70. Bae KH, Kim JG, Park KG. Transcriptional Regulation of Fibroblast Growth Factor 21 Expression. Endocrinol Metab (Seoul) (2014) 29:105-11. doi: 10.3803/EnM.2014.29.2.105

71. Adams AC, Kharitonenkov A. FGF21: The Center of a Transcriptional Nexus in Metabolic Regulation. Curr Diabetes Rev (2012) 8:285-93. doi: 10.2174/ 157339912800840505

72. Wanders D, Stone KP, Forney LA, Cortez CC, Dille KN, Simon J, et al. Role of GCN2-Independent Signaling Through a Non-Canonical PERK/NRF2 Pathway in the Physiological Responses to Dietary Methionine Restriction. Diabetes (2016) 65:1499-510. doi: 10.2337/db15-1324

73. Chalvon-Demersay T, Moro J, Even PC, Chaumontet C, Tome D, Averous J, et al. Liver GCN2 Controls Hepatic FGF21 Secretion and Modulates Whole Body Postprandial Oxidation Profile Under a Low-Protein Diet. Am J Physiol Endocrinol Metab (2019) 317:E1015-21. doi: 10.1152/ajpendo.00022.2019

74. Forney LA, Stone KP, Wanders D, Gettys TW. Sensing and Signaling Mechanisms Linking Dietary Methionine Restriction to the Behavioral and Physiological Components of the Response. Front Neuroendocrinol (2018) 51:36-45. doi: 10.1016/j.yfrne.2017.12.002

75. Ables GP, Johnson JE. Pleiotropic Responses to Methionine Restriction. Exp Gerontol (2017) 94:83-8. doi: 10.1016/j.exger.2017.01.012

76. Yap YW, Rusu PM, Chan AY, Fam BC, Jungmann A, Solon-Biet SM, et al. Restriction of Essential Amino Acids Dictates the Systemic Metabolic Response to Dietary Protein Dilution. Nat Commun (2020) 11:2894. doi: $10.1038 / \mathrm{s} 41467-020-16568-\mathrm{z}$

77. Laeger T, Henagan TM, Albarado DC, Redman LM, Bray GA, Noland RC, et al. FGF21 Is an Endocrine Signal of Protein Restriction. J Clin Invest (2014) 124:3913-22. doi: 10.1172/Jci74915

78. Fang H, Stone KP, Ghosh S, Forney LA, Gettys TW. The Role of Reduced Methionine in Mediating the Metabolic Responses to Protein Restriction Using Different Sources of Protein. Nutrients (2021) 13:1-19. doi: 10.3390/ nu13082609

79. Perrone CE, Mattocks DA, Plummer JD, Chittur SV, Mohney R, Vignola K, et al. Genomic and Metabolic Responses to Methionine-Restricted and Methionine-Restricted, Cysteine-Supplemented Diets in Fischer 344 Rat Inguinal Adipose Tissue, Liver and Quadriceps Muscle. J Nutrigenet Nutrigenomics (2012) 5:132-57. doi: 10.1159/000339347

80. Stone KP, Wanders D, Orgeron M, Cortez CC, Gettys TW. Mechanisms of Increased In Vivo Insulin Sensitivity by Dietary Methionine Restriction in Mice. Diabetes (2014) 63:3721-33. doi: 10.2337/db14-0464

81. Solon-Biet SM, McMahon AC, Ballard JW, Ruohonen K, Wu LE, Cogger VC, et al. The Ratio of Macronutrients, Not Caloric Intake, Dictates Cardiometabolic Health, Aging, and Longevity in Ad Libitum-Fed Mice. Cell Metab (2014) 19:418-30. doi: 10.1016/j.cmet.2014.02.009

82. Wanders D, Forney LA, Stone KP, Hasek BE, Johnson WD, Gettys TW. The Components of Age-Dependent Effects of Dietary Methionine Restriction on Energy Balance in Rats. Obes (Silver Spring) (2018) 26:740-6. doi: 10.1002/ oby.22146 
83. Ghosh S, Wanders D, Stone KP, Van NT, Cortez CC, Gettys TW. A Systems Biology Analysis of the Unique and Overlapping Transcriptional Responses to Caloric Restriction and Dietary Methionine Restriction in Rats. FASEB J (2014) 28:2577-90. doi: 10.1096/fj.14-249458

84. Laeger T, Albarado DC, Burke SJ, Trosclair L, Hedgepeth JW, Berthoud HR, et al. Metabolic Responses to Dietary Protein Restriction Require an Increase in FGF21 That Is Delayed by the Absence of GCN2. Cell Rep (2016) 16:70716. doi: 10.1016/j.celrep.2016.06.044

85. Maida A, Zota A, Sjoberg KA, Schumacher J, Sijmonsma TP, Pfenninger A, et al. A Liver Stress-Endocrine Nexus Promotes Metabolic Integrity During Dietary Protein Dilution. J Clin Invest (2016) 126:3263-78. doi: 10.1172/JCI85946

86. Forney LA, Fang H, Sims LC, Stone KP, Vincik LY, Vick AM, et al. Dietary Methionine Restriction Signals to the Brain Through Fibroblast Growth Factor 21 to Regulate Energy Balance and Remodeling of Adipose Tissue. Obes (Silver Spring) (2020) 28:1912-21. doi: 10.1002/oby.22919

87. Berry SA, Brown CS, Greene C, Camp KM, McDonough S, Bocchini JA Jr Follow, U.; Treatment Workgroup for the Advisory Committee on Heritable Disorders in, N.; Children. Medical Foods for Inborn Errors of Metabolism: History, Current Status, and Critical Need. Pediatrics (2020) 145:1-8. doi: 10.1542/peds.2019-2261

88. Plaisance EP, Greenway FL, Boudreau A, Hill KL, Johnson WD, Krajcik RA, et al. Dietary Methionine Restriction Increases Fat Oxidation in Obese Adults With Metabolic Syndrome. J Clin Endocrinol Metab (2011) 96:E836-840. doi: 10.1210/jc.2010-2493

89. Finkelstein JD, Martin JJ, Harris BJ. Methionine Metabolism in Mammals. The Methionine-Sparing Effect of Cystine. J Biol Chem (1988) 263:11750-4. doi: 10.1016/S0021-9258(18)37847-5

90. Elshorbagy AK, Valdivia-Garcia M, Mattocks DA, Plummer JD, Smith AD, Drevon CA, et al. Cysteine Supplementation Reverses Methionine Restriction Effects on Rat Adiposity: Significance of Stearoyl-Coenzyme a Desaturase. J Lipid Res (2011) 52:104-12. doi: 10.1194/jlr.M010215

91. Elshorbagy AK, Valdivia-Garcia M, Mattocks DA, Plummer JD, Orentreich DS, Orentreich N, et al. Effect of Taurine and N-Acetylcysteine on Methionine Restriction-Mediated Adiposity Resistance. Metabolism (2013) 62:509-17. doi: 10.1016/j.metabol.2012.10.005
92. Fang H, Stone KP, Forney LA, Sims LC, Gutierrez GC, Ghosh S, et al. Implementation of Dietary Methionine Restriction Using Casein After Selective, Oxidative Deletion of Methionine. iScience (2021) 24:102470. doi: 10.1016/j.isci.2021.102470

93. Geller S, Arribat Y, Netzahualcoyotzi C, Lagarrigue S, Carneiro L, Zhang L, et al. Tanycytes Regulate Lipid Homeostasis by Sensing Free Fatty Acids and Signaling to Key Hypothalamic Neuronal Populations via FGF21 Secretion. Cell Metab (2019) 30:833-844 e837. doi: 10.1016/j.cmet.2019.08.004

94. Jensen-Cody SO, Flippo KH, Claflin KE, Yavuz Y, Sapouckey SA, Walters GC, et al. FGF21 Signals to Glutamatergic Neurons in the Ventromedial Hypothalamus to Suppress Carbohydrate Intake. Cell Metab (2020) 32:27386.e276. doi: 10.1016/j.cmet.2020.06.008

95. Santoso P, Nakata M, Shiizaki K, Boyang Z, Parmila K, Otgon-Uul Z, et al. Fibroblast Growth Factor 21, Assisted by Elevated Glucose, Activates Paraventricular Nucleus NUCB2/Nesfatin-1 Neurons to Produce Satiety Under Fed States. Sci Rep (2017) 7:45819. doi: 10.1038/srep45819

Conflict of Interest: The authors declare that the research was conducted in the absence of any commercial or financial relationships that could be construed as a potential conflict of interest.

Publisher's Note: All claims expressed in this article are solely those of the authors and do not necessarily represent those of their affiliated organizations, or those of the publisher, the editors and the reviewers. Any product that may be evaluated in this article, or claim that may be made by its manufacturer, is not guaranteed or endorsed by the publisher.

Copyright (c) 2021 Fang, Stone, Forney, Wanders and Gettys. This is an open-access article distributed under the terms of the Creative Commons Attribution License (CC BY). The use, distribution or reproduction in other forums is permitted, provided the original author(s) and the copyright owner(s) are credited and that the original publication in this journal is cited, in accordance with accepted academic practice. No use, distribution or reproduction is permitted which does not comply with these terms. 